\title{
Chronic Recanalization of Dissection of the Distal Anterior Cerebral Artery: Case Report and Review of the Literature
}

\author{
Shuichiro Asano ${ }^{1,2}$ and Tetsuo Hara ${ }^{1}$ \\ ${ }^{1}$ Department of Neurosurgery, Toyama Hospital, International Medical Center of Japan, Tokyo 162-8655, Japan \\ ${ }^{2}$ Department of Neurosurgery, Tokyo Kosei-Nenkin Hospital, 5-1 Tsukudo-cho, Shinjuku-ku, Tokyo 162-8543, Japan \\ Correspondence should be addressed to Shuichiro Asano, sasano-tky@umin.ac.jp
}

Received 26 March 2009; Accepted 16 July 2009

Recommended by Aaron S. Dumont

The natural history of atraumatic idiopathic dissection of the distal anterior cerebral artery is still unclear. We present a 38-yearold man who had dissection of the left $\mathrm{A}_{2}$ segment of this vessel associated with subintimal hematoma and infarction. Because of complete stroke in acute stage, he did not undergo surgery. About three months later, administration of aspirin ( $100 \mathrm{mg} / \mathrm{day}$ ) was started. At nine months, magnetic resonance angiography revealed complete recanalization of the $\mathrm{A}_{2}$ dissection. To assess the outcome of dissection, we should observe the patient for at least one year.

Copyright (C) 2009 S. Asano and T. Hara. This is an open access article distributed under the Creative Commons Attribution License, which permits unrestricted use, distribution, and reproduction in any medium, provided the original work is properly cited.

\section{Introduction}

Atraumatic intracranial dissecting aneurysm mainly occurs in the vertebrobasilar or internal carotid arteries [1]. Although reports about dissecting aneurysms of the distal anterior cerebral artery have been gradually increasing, especially in Japan, the clinical course and treatment of this lesion are still unclear. We report an unusual case of dissection of the distal anterior cerebral artery that showed angiographic recovery by 9 months after the onset with antiplatelet therapy alone. We also review the relevant literature.

\section{Case Report}

While urinating, a 38-year-old man suffered from the sudden onset of severe headache, difficulty speaking, and right hemiparesis (the lower extremity was more severely affected). He was taken to a local hospital by ambulance. Computed tomography (CT) showed thin subarachnoid hemorrhage (SAH) on the left side of the interhemispheric fissure (Fisher's group 2 [2]) (Figure 1(a)). Magnetic resonance imaging (MRI) revealed left frontal lobe infarction (Figure 1(b)), and cerebral angiography indicated stenosis (string sign) of the distal left anterior cerebral artery $\left(\mathrm{A}_{2}\right.$ segment) (Figure 1(c)). A tentative diagnosis of idiopathic SAH with early spasm of the left $\mathrm{A}_{2}$ segment was made. After two weeks of medical treatment, repeat cerebral angiography showed no source of SAH and persistent $\mathrm{A}_{2}$ stenosis. His speech improved, but right hemiparesis persisted. After transfer to a rehabilitation hospital, it was decided to reexamine his condition and he was admitted to our hospital.

On admission, he had right hemiparesis ( $4 / 5$ for the upper limb on manual muscle testing and $2 / 5$ for the lower limb). MRI showed medial left frontal lobe infarction with poor perfusion of the left $\mathrm{A}_{2}$ segment (Figure 2(a)). Angiography also revealed severe stenosis (string sign) of the left $\mathrm{A}_{2}$ segment (Figure 2(b)). Because the string sign without pear appearance (stenosis without dilation) warranted the diagnosis of the dissecting aneurysm by some articles [3-5], the final diagnosis was dissection of the left $\mathrm{A}_{2}$ segment of the anterior cerebral artery. Because his clinical status was stable, he was returned to the rehabilitation hospital.

Two months later, he was reviewed at our outpatient clinic. His right upper limb was recovered but his right lower limb was $3+\sim 4 / 5$ on manual muscle testing. Because the left distal anterior cerebral artery did not recanalize at that time, aspirin $(100 \mathrm{mg} /$ day $)$ was commenced. Six months later, magnetic resonance angiography (MRA) showed recanalization of the left $\mathrm{A}_{2}$ segment (Figure 2(c)). Because repeat 


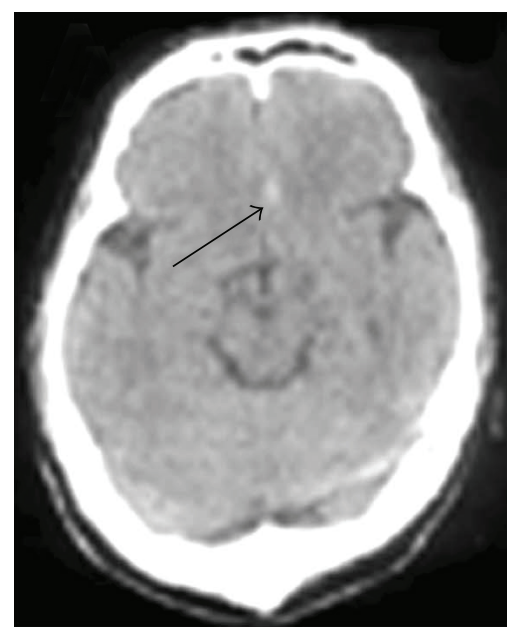

(a)

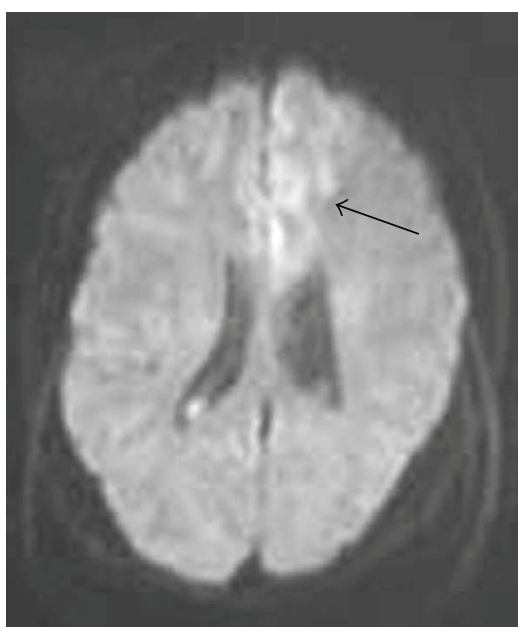

(b)

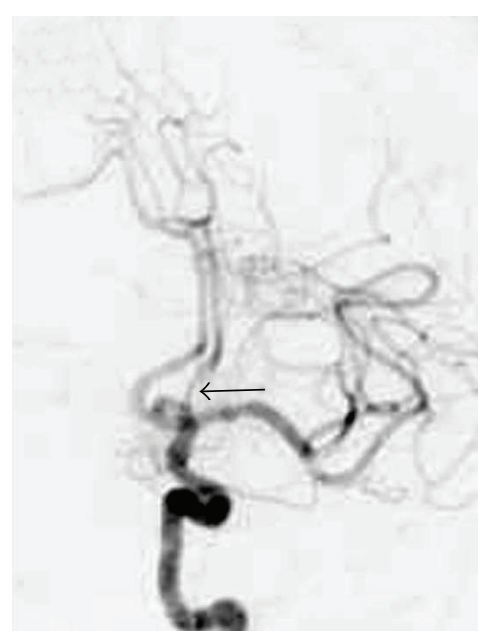

(c)

FIGURE 1: Imaging findings on the day of onset. (a) Computed tomography shows very thin subarachnoid hemorrhage on the left side of the interhemispheric fissure (arrow). (b) Magnetic resonance imaging (diffusion image) reveals infarction of the left medial frontal region (arrow). (c) Left internal cerebral artery angiography reveals stenosis (string sign) of the $\mathrm{A}_{2}$ segment (arrow).

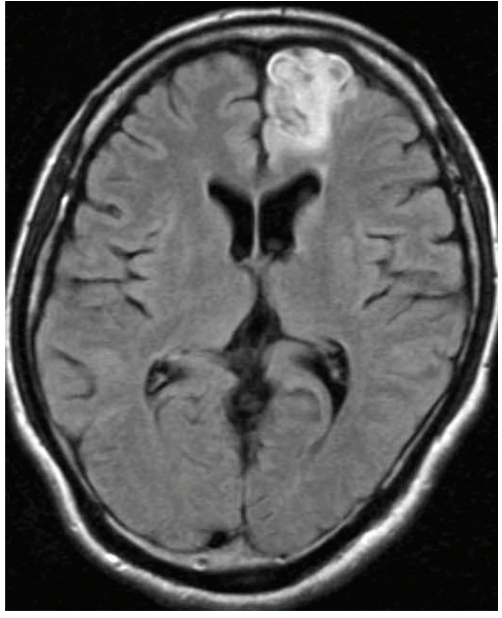

(a)

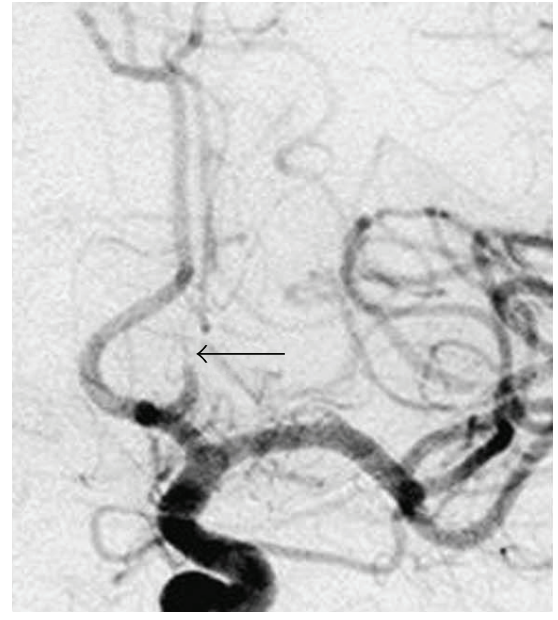

(b)

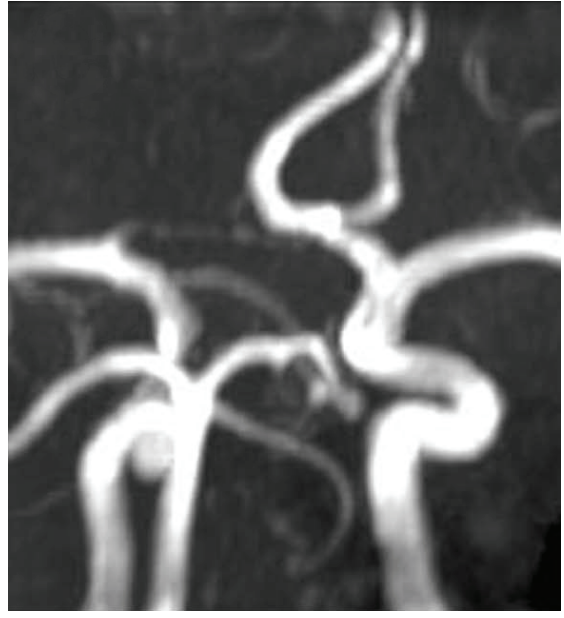

(c)

FIGURE 2: (a) Magnetic resonance imaging (FLAIR sequence) about one month after the onset shows infarction of the medial part of the left frontal lobe. (b) Left internal cerebral artery angiogram displays severe stenosis of the $\mathrm{A}_{2}$ segment (arrow). (c) About 9 months after the onset, magnetic resonance angiography reveals recanalization of the left $\mathrm{A}_{2}$ segment.

MRA also showed patency of the left $A_{2}$ segment one year later, aspirin therapy was ceased. There have been no new neurological problems during followup.

\section{Discussion}

The present patient had a dissection of the distal anterior cerebral artery that showed angiographic recanalization in the chronic stage with antiplatelet therapy alone.

We identified 42 detailed reports of atraumatic distal anterior cerebral artery dissection in patients without collagen diseases (including our case, Table 1) [6-40]. Their mean age was 47.3 years (SD 8.5), and the female:male ratio was approximately $1 / 4$ ( 8 women [6-13], and 34 men $[6,14-40])$. Only one patient was reported from outside Japan [7]. There were 30 cases of cerebral infarction alone $[6,8,12-34]$, six cases of hemorrhage alone [7, 9, 14, 35-37], and six cases of both infarction and hemorrhage (including our case) $[10,11,38-40]$. In the infarction only group, 20 patients did not have surgery $[6,8,12,14-27]$, and the other 10 underwent surgical intervention (wrapping in two cases $[15,32], A_{3}-A_{3}$ bypass and trapping in five cases [28-31], and trapping only in three cases $[13,33,34])$. Among the patients with infarction alone and conservative treatment, only three cases of angiographic improvement were reported $[14,16,17]$. In one of these three patients, urokinase (180,000 units/day) was administered for one week after 
TABLE 1: Items of the atraumatic distal anterior cerebral artery dissection with 42 detailed cases reports (including our case).

\begin{tabular}{|c|c|c|c|c|c|}
\hline & $\begin{array}{c}\text { Conservative } \\
\text { treatment } \\
\text { group }\end{array}$ & $\begin{array}{c}\text { Conservative } \\
\text { treatment } \\
\text { group }\end{array}$ & $\begin{array}{c}\text { Surgical } \\
\text { intervention } \\
\text { group }\end{array}$ & $\begin{array}{c}\text { Surgical } \\
\text { intervention } \\
\text { group }\end{array}$ & $\begin{array}{c}\text { Surgical } \\
\text { intervention } \\
\text { group }\end{array}$ \\
\hline & Recanalized & Not recanalized & Wrapping & $\begin{array}{c}\mathrm{A}_{3}-\mathrm{A}_{3} \text { bypass } \& \\
\text { trapping }\end{array}$ & Trapping \\
\hline Infarction onset & 3 & 17 & 2 & 5 & 3 \\
\hline $\mathrm{SAH}$ with $\mathrm{A}_{2}$ dissection onset & 0 & 0 & 1 & 1 & 0 \\
\hline $\mathrm{ICH}$ with $\mathrm{A}_{4}$ dissection onset & 0 & 4 & 0 & 0 & 0 \\
\hline Infarction with SAH onset & 2 & 1 & 1 & 1 & 0 \\
\hline Infarction with $\mathrm{ICH}$ onset & 0 & 1 & 0 & 0 & 0 \\
\hline
\end{tabular}

SAH: subarachnoid hemorrhage, ICH: intracerebral hemorrhage.

infarction [16], antihypertensive and antiplatelet therapies were administered for six months in another patient [17], and ticlopidine $(200 \mathrm{mg} /$ day $)$ was administered for 8 months to the third patient [14]. The period until angiographic recovery was three months, six months, and 8 months, respectively.

The patients who had hemorrhage alone included four with intracerebral hemorrhage (ICH) $[7,9,35,36]$, and two with SAH $[14,37]$. All four patients with ICH had dissection of the $\mathrm{A}_{4}$ segment. Both SAH patients had dissection of the $A_{2}$ segment, but they were neurologically normal while the other patients suffered from infarction and hemiparesis. $\mathrm{A}_{3}-$ $\mathrm{A}_{3}$ bypass and trapping was done in one SAH patient [37], and wrapping was performed for the other [14].

The combined hemorrhage and infarction group comprised five patients (including ours) with $\mathrm{SAH}$ and infarction $[10,11,38,39]$, as well as one patient with $\mathrm{ICH}$ and infarction who did not undergo surgery [40]. $\mathrm{A}_{3}-\mathrm{A}_{3}$ bypass and trapping was done in one patient with $\mathrm{SAH}$ and infarction [39], wrapping was performed in one [38], and three patients (including ours) were managed conservatively $[10,11]$. Among the last three patients, recanalization of the dissection was confirmed in two, with one receiving no antiplatelet or anticoagulant therapy [10] and the other being our patient. The period from the onset until angiographic confirmation of recanalization was 18 months and 9 months, respectively.

We found five patients with infarction (including our case) who had confirmed recanalization of the dissection after conservative treatment $[10,14,16,17]$, while the dissecting aneurysm persisted in 19 patients $[6,8,11,12$, $14,15,18-27,40]$. The median period until angiographic recanalization was 8 months (25th-75th percentile: $5.3-11.3$ months; range: 3-18 months), while the median period until final angiography in the other 19 patients was only two months (25th-75th percentile: $1.5-4.0$ months; range: 0.7-96 months) and the difference was significant $(P=$ .029, Mann-Whitney $U$-test). Therefore, the angiographic cure rate of distal anterior cerebral artery dissection after conservative treatment may be increased by continuing followup for at least one year.

Although anticoagulation and/or antiplatelet medication may be a widely accepted conservative management for intracranial arterial dissection with purely ischemic symp- tom, two patients with infarction onset died of adverse drug reactions. One was administered sodium ozagrel ( $80 \mathrm{mg} /$ day) for 12 days after infarction, but severe SAH occurred on the 12th day [13]. Another patient received antithrombin therapy in the acute stage, followed by an antiplatelet drug. On day 21 after the onset, he suffered from severe ICH [6]. On the other hand, 11 patients were safely administered urokinase [16], ozagrel $[11,18-20]$, heparin $[21,22]$, argatroban [12], ticlopidine [14], aspirin [12, 14, 21], or antiplatelet drugs [17] during the acute stage. Three of these 11 patients achieved angiographic cure $[14,16,17]$. These results suggest that we must pay close attention when using these drugs in the acute stage of distal anterior cerebral artery dissection.

\section{Conclusion}

We reported a patient with dissection of the anterior cerebral artery $\left(A_{2}\right.$ segment $)$ who showed recanalization after 9 months with only aspirin therapy. It may be important to monitor such patients for at least one year to determine the clinical outcome.

\section{References}

[1] A. Yamaura, J. Ono, and S. Hirai, "Clinical picture of intracranial non-traumatic dissecting aneurysm," Neuropathology, vol. 20, no. 1, pp. 85-90, 2000.

[2] C. M. Fisher, J. P. Kistler, and J. M. Davis, "Relation of cerebral vasospasm to subarachnoid hemorrhage visualized by computerized tomographic scanning," Neurosurgery, vol. 6, no. 1, pp. 1-9, 1980.

[3] H. Ohkuma, S. Suzuki, T. Kikkawa, and N. Shimamura, "Neuroradiologic and clinical features of arterial dissection of the anterior cerebral artery," American Journal of Neuroradiology, vol. 24, no. 4, pp. 691-699, 2003.

[4] E. V. Spudis, M. Scharyi, E. Alexander, and J. F. Martin, "Dissecting aneurysms in the neck and head," Neurology, vol. 12, pp. 867-875, 1962.

[5] H. Yonas, D. Agamanolis, Y. Takaoka, and R. J. White, "Dissecting intracranial aneurysms," Surgical Neurology, vol. 8, no. 6, pp. 407-415, 1977.

[6] I. Suzuki, A. Nishino, S. Nishimura, et al., "Nontraumatic arterial dissection of the anterior cerebral artery: six cases 
report," Brain and Nerve, vol. 57, no. 6, pp. 509-515, 2005 (Japanese).

[7] J. Guridi, J. Gállego, F. Monzón, and F. Aguilera, "Intracerebral hemorrhage caused by transmural dissection of the anterior cerebral artery," Stroke, vol. 24, no. 9, pp. 1400-1402, 1993.

[8] S. Sakamoto, T. Inagawa, F. Ikawa, et al., "Dissecting aneurysm of the anterior cerebral artery with persistent pearl \& string sign on cerebral angiograms over a period of eight years," Neurological Surgery, vol. 29, no. 11, pp. 1093-1098, 2001 (Japanese).

[9] S. Sakamoto, T. Inagawa, F. Ikawa, H. Kawamoto, and N. Ohbayashi, "Anterior cerebral artery dissections manifesting as cerebral hemorrhage and infarction, and presenting as dynamic angiographical changes: case report," Neurologia Medico-Chirurgica, vol. 42, no. 6, pp. 250-254, 2002.

[10] N. Moro, Y. Katayama, H. Oshima, and T. Kano, "Sagittal magnetic resonance imaging of intramural hematoma from non-traumatic dissection of the anterior cerebral artery: case report," Neurologia Medico-Chirurgica, vol. 45, no. 6, pp. 300 305, 2005.

[11] N. Kato, Y. Yamada, A. Hyodo, and T. Nose, "A case of anterior cerebral artery dissection presenting subarachnoid hemorrhage and cerebral infarction," Japanese Journal of Neurosurgery, vol. 9, no. 3, pp. 157-161, 2000 (Japanese).

[12] M. Oomura, T. Terai, T. Yamawaki, and K. Shigeno, "A case of anterior cerebral artery dissection causing enlargement of infarction," Clinical Neurology, vol. 45, no. 10, pp. 762-765, 2005 (Japanese).

[13] S. M. Yamada, M. Nakane, M. Aoki, and H. Nakayama, "Dissecting aneurysm of the anterior cerebral artery with severe subarachnoid hemorrhage during treatment for cerebral infarction," Internal Medicine, vol. 42, no. 5, pp. 433-435, 2003.

[14] K. Mori, T. Yamamoto, and M. Maeda, "Dissecting aneurysm confined to the anterior cerebral artery," British Journal of Neurosurgery, vol. 16, no. 2, pp. 158-164, 2002.

[15] M. Kidooka, T. Okada, M. Sonobe, T. Nakazawa, and J. Handa, "Dissecting aneurysm of the anterior cerebral artery: report of two cases," Surgical Neurology, vol. 39, no. 1, pp. 53-57, 1993.

[16] O. Sasaki, T. Koike, S. Takeuchi, and R. Tanaka, "Serial angiography in a spontaneous dissecting anterior cerebral artery aneurysm," Surgical Neurology, vol. 36, no. 1, pp. 49-53, 1991.

[17] M. Kurino, S. Yoshioka, and Y. Ushio, "Spontaneous dissecting aneurysms of anterior and middle cerebral artery associated with brain infarction: a case report and review of the literature," Surgical Neurology, vol. 57, no. 6, pp. 428-436, 2002.

[18] T. Araki, M. Ouchi, and Y. Ikeda, "A case of anterior cerebral artery dissecting aneurysm," Neurological Surgery, vol. 24, no. 1, pp. 87-91, 1996 (Japanese).

[19] H. Kanai, K. Koide, Y. Niwa, and M. Umezu, "Spontaneous dissection of the A2 segment of the anterior cerebral artery presenting cerebral infarction: a case report," Japanese Journal of Neurosurgery, vol. 8, no. 11, pp. 732-737, 1999 (Japanese).

[20] S. Yamaguchi, S. Oki, T. Mikami, Y. Kawamoto, Y. Ito, and K. Kuwamoto, "A case of an intracranial dissecting aneurysm localized in the anterior cerebral artery," Japanese Journal of Neurosurgery, vol. 7, no. 4, pp. 230-234, 1998 (Japanese).

[21] M. Oomura, T. Terai, K. Shigeno, and T. Yamawaki, "A case of anterior cerebral artery dissection causing hemorrhagic infarction," Clinical Neurology, vol. 45, no. 1, pp. 41-44, 2005 (Japanese).
[22] S. Matsumoto, T. Takada, K. Minematsu, et al., "Threedimensional rotational angiography for evaluating dissecting aneurysm of anterior cerebral artery," Brain Circulation, vol. 6, pp. 251-253, 2001 (Japanese).

[23] S. Koyama, A. Kotani, and J. Sasaki, "Spontaneous dissecting aneurysm of the anterior cerebral artery: report of two cases," Surgical Neurology, vol. 46, no. 1, pp. 55-61, 1996.

[24] K. Nakanishi, T. Uchiyama, F. Akai, et al., "Dissecting aneurysm of the anterior cerebral artery with later development of collateral circulation: a case report," Neurological Surgery, vol. 29, no. 8, pp. 781-785, 2001 (Japanese).

[25] T. Nakazawa, A. Saito, K. Watanabe, M. Matsuda, and J. Handa, "Dissecting aneurysm of the anterior cerebral artery: report of a case," Neurological Surgery, vol. 12, no. 10, pp. 1211-1216, 1984 (Japanese).

[26] S. Terai and T. Matsubara, "A case of dissecting aneurysm involving solely anterior cerebral artery," Japanese Journal of Stroke, vol. 13, pp. 159-164, 1991 (Japanese).

[27] Y. Tominaga, A. Uchino, Y. Takase, et al., "Presumed anterior cerebral artery dissection: a case report," Japanese Journal of Clinical Radiology, vol. 45, no. 9, pp. 1094-1098, 2000 (Japanese).

[28] Y. Kohama, S. Kaneko, H. Kobayashi, et al., "A case of anterior cerebral artery dissecting aneurysm," Iwamizawa City General Hospital Medical Journal, vol. 22, pp. 95-102, 1996 (Japanese).

[29] K. Nagata and K. Sato, "Surgical treatment for the dissecting aneurysm of the anterior cerebral artery," Surgery for Cerebral Stroke, vol. 24, pp. 80-84, 1996 (Japanese).

[30] R. Tanikawa, R. Anei, N. Izumi, et al., "Strategy of treatment for anterior cerebral artery dissection," Surgery for Cerebral Stroke, vol. 27, pp. 433-438, 1999 (Japanese).

[31] H. Wada, R. Tanikawa, T. Ishizaki, et al., "A case of anterior cerebral artery dissection presenting recurrent transient ischemic attack," Surgery for Cerebral Stroke, vol. 26, pp. 444448, 1998 (Japanese).

[32] R. Ishikawa, S. Sunagawa, I. Itoh, and K. Iwashita, "An experience of dissecting cerebral aneurysm of the anterior cerebral artery," Neurological Surgery, vol. 21, no. 4, pp. 355359, 1993 (Japanese).

[33] S. Okuno, C. Ochiai, and M. Nagai, "Dissecting aneurysm of the anterior cerebral artery causing hemorrhagic infarction," Surgical Neurology, vol. 45, no. 1, pp. 25-30, 1996.

[34] Y. Wakabayashi, T. Nakano, M. Isono, T. Shimomura, and S. Hori, "Dissecting aneurysm of the anterior cerebral artery requiring surgical treatment-case report," Neurologia Medico-Chirurgica, vol. 40, no. 12, pp. 624-627, 2000.

[35] K. Amagasaki, T. Yagishita, S. Yagi, K. Kuroda, K. Nishigaya, and H. Nukui, "Serial angiography and endovascular treatment of dissecting aneurysms of the anterior cerebral and vertebral arteries: case report," Journal of Neurosurgery, vol. 91, no. 4, pp. 682-686, 1999.

[36] H. Yano, M. Sawada, J. Shinoda, and T. Funakoshi, "Ruptured dissecting aneurysm of the peripheral anterior cerebral artery-case report," Neurologia Medico-Chirurgica, vol. 35, no. 7, pp. 450-453, 1995.

[37] T. Mizutani, H. Kojima, S. Asamoto, and Y. Miki, "Pathological mechanism and three-dimensional structure of cerebral dissecting aneurysms," Journal of Neurosurgery, vol. 94, no. 5, pp. 712-717, 2001.

[38] K. Miyahara, K. Sakata, G. Gondo, H. Kanno, and I. Yamamoto, "Spontaneous dissection of the anterior cerebral artery presenting subarachnoid hemorrhage and cerebral infarction: a case report," Neurological Surgery, vol. 29, no. 4, pp. 335-339, 2001 (Japanese). 
[39] K. Yasukawa, Y. Kamijo, G. Momose, et al., "A case of anterior cerebral artery dissecting aneurysm presenting subarachnoid hemorrhage and cerebral infarction at the same time," Surgery for Cerebral Stroke, vol. 21, pp. 461-466, 1993 (Japanese).

[40] N. Hayashi, O. Fukuda, S. End, and A. Takaku, "Intracerebral hemorrhage secondary to dissecting aneurysm of the anterior cerebral artery," Brain and Nerve, vol. 48, no. 11, pp. 10531056, 1996 (Japanese). 


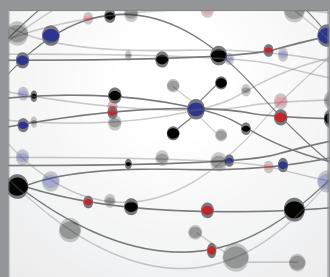

The Scientific World Journal
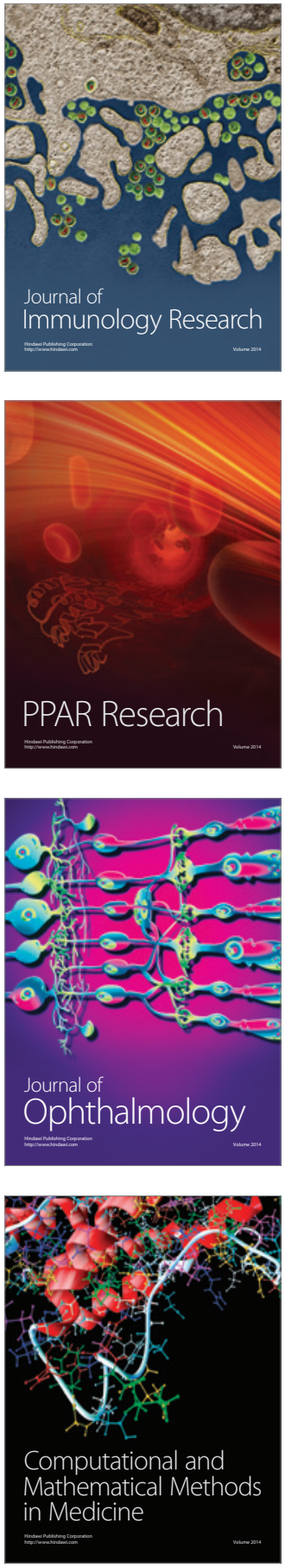

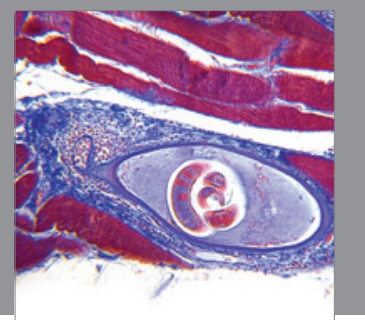

Gastroenterology

Research and Practice
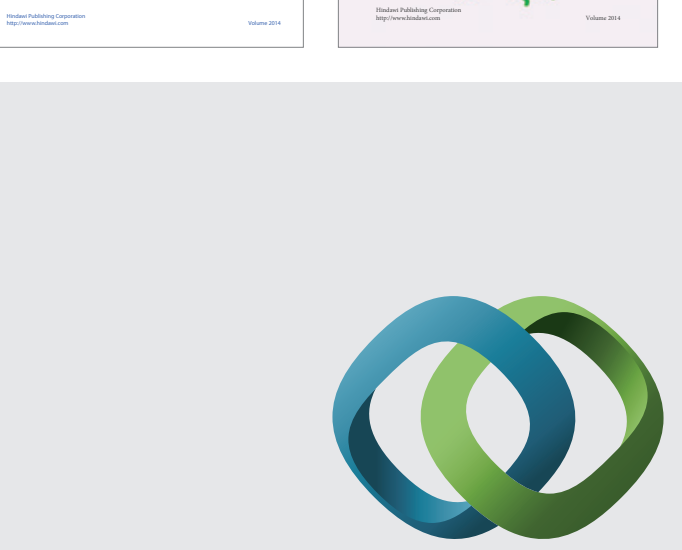

\section{Hindawi}

Submit your manuscripts at

http://www.hindawi.com
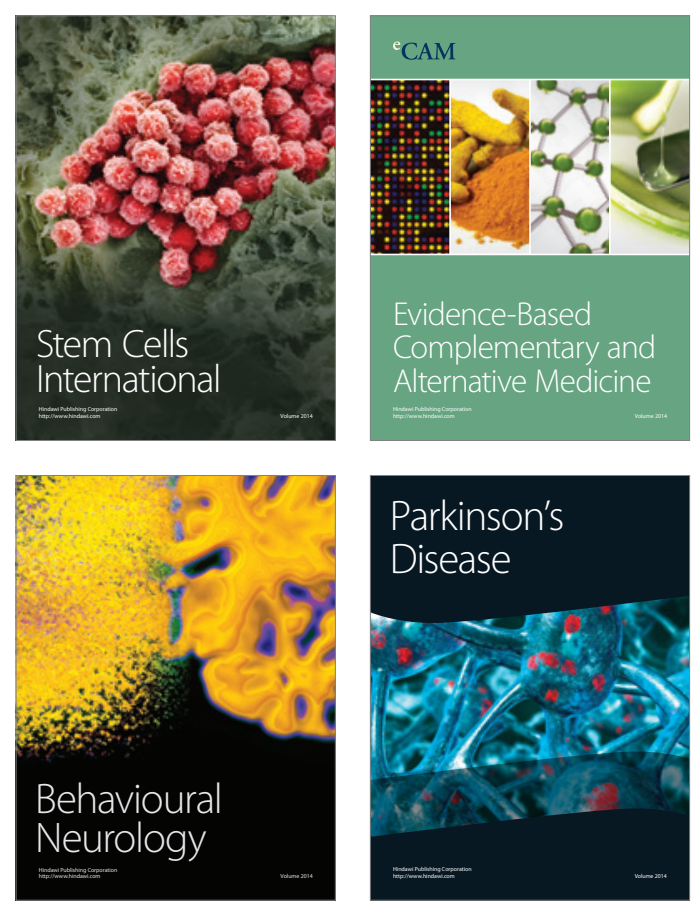

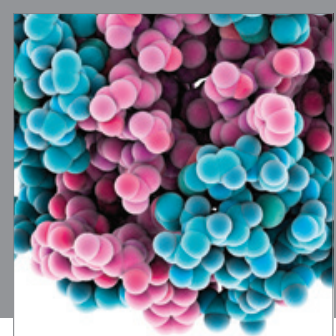

Journal of
Diabetes Research

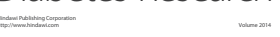

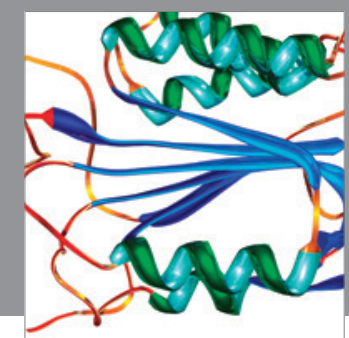

Disease Markers
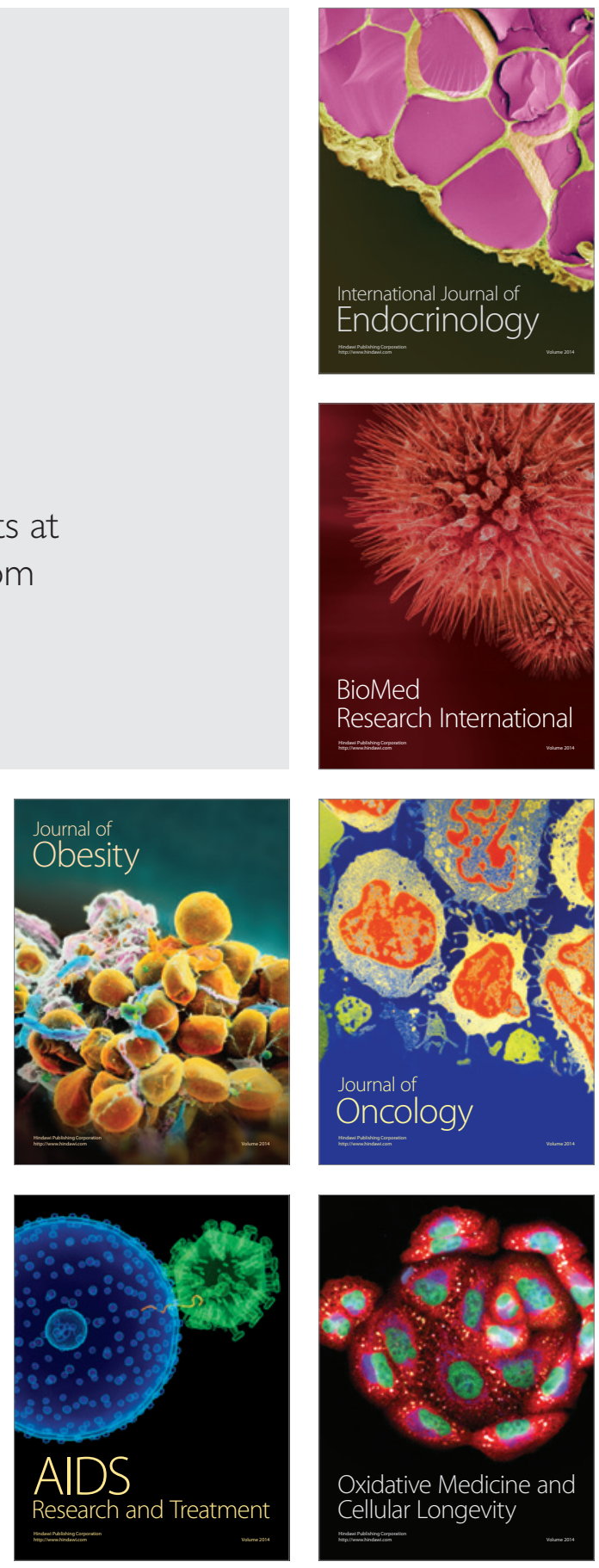